\title{
Effectiveness of forceps delivery in modern day obstetrics
}

\section{Devdatt Laxman Pitale*}

Department of Obstetrics and Gynecology, INHS Asvini, Mumbai, Maharashtra, India

Received: 03 April 2020

Accepted: 29 April 2020

\section{*Correspondence:}

Dr. Devdatt Laxman Pitale,

E-mail: dipu.pitale@gmail.com

Copyright: (c) the author(s), publisher and licensee Medip Academy. This is an open-access article distributed under the terms of the Creative Commons Attribution Non-Commercial License, which permits unrestricted non-commercial use, distribution, and reproduction in any medium, provided the original work is properly cited.

\section{ABSTRACT}

Background: There has been an alarming rise in number of caesarean sections all over the world. Instrumental delivery plays an important role to reduce this trend globally. Forceps delivery though proper training and expertise can definitely reduce the rising caesarean section rates in the modern-day obstetrics. The aim of this study is to study the effectiveness of forceps delivery in modern obstetrics.

Methods: In the present observational study, 20 cases of forceps delivery were studied for maternal and foetal outcomes including postpartum hemorrhage, perineal tears, Apgar score, NICU admissions, birth injury, and mortality.

Results: The most common indication for forceps application was maternal exhaustion (80\%) followed by foetal distress. All the cases of forceps application in the present study were associated uneventful vaginal delivery. No any adverse maternal outcomes including perineal tears, post-partum hemorrhage was observed in this study. Average birth weight in the present study was $3.2 \mathrm{kgs}$ and Apgar scores at birth and five minutes was within normal limits. No any birth injury was noted in any of the newborns.

Conclusions: Forceps delivery is a safe and effective option in modern day obstetrics to reduce the alarming rise in rates of caesarean section globally. Training should be encouraged to develop the expertise of this art of forceps delivery.

Keywords: Foetal outcome, Forceps, Maternal outcome

\section{INTRODUCTION}

There has been an alarming rise in number of caesarean sections all over the world. ${ }^{1,2}$ As a result of this instrumental deliveries have declined notably. ${ }^{2}$ Forceps delivery though proper training and expertise can definitely reduce the rising caesarean section rates in the modern-day obstetrics. Forceps delivery has a higher rate of success as compared to vacuum delivery. ${ }^{3}$ Forceps have been a very important component of obstetrics practice for ages. A large number of women have been benefited from timely and uneventful forceps delivery. In modern day obstetrics authors should make every possible effort to retain, to train and improvise this art of forceps delivery in every possible way. This will be of prime benefit for the future generations and cornerstone of safe modern obstetrics. ${ }^{4}$
The aim of this study was to study the effectiveness of forceps delivery in modern obstetrics.

\section{METHODS}

This is a prospective observational study. 20 cases of properly selected antenatal cases at term attending the obstetrics department over period of 3 years from February 2017 to February 2020 who satisfied the inclusion and exclusion criteria were included in the present study.

\section{Inclusion criteria}

- Term gestation

- Singleton gestation 
- Cephalic presentation.

\section{Exclusion criteria}

- Multi-foetal gestation

- Breech presentation.

The indications and outcomes were noted. The parameters of maternal and foetal outcomes were studied including perineal trauma, postpartum hemorrhage (PPH), Apgar scores at birth, injuries, NICU admission and mortality.

\section{Statistical analysis}

The statistical analysis of the data thus collected is done by observational method of data analysis and computed in results respectively.

\section{RESULTS}

A total of 20 cases were studied in the present study. The number of primigravida's were $15(75 \%)$ and mean age at delivery was 23 years. Outlet forceps were applied in all the cases studied in the present study after following standard protocol and guidelines. The most common indication for forceps application was maternal exhaustion /failure of secondary powers $(80 \%)$ followed by fetal distress and prolonged second stage of labour in $(10 \%)$ cases respectively.

The indications for forceps application are shown in Table 1.

Table 1: Indications forceps delivery.

\begin{tabular}{|ll|}
\hline Indications & Number of patients \\
\hline Maternal exhaustion & $16(80 \%)$ \\
\hline Foetal distress & $2(10 \%)$ \\
\hline Prolonged second stage & $2(10 \%)$ \\
\hline
\end{tabular}

\section{Parity status}

The parity status of women who underwent forceps delivery in the present study is shown in table 2.15 women in the present study were primigravida and the average age at delivery as shown in table 3 was 23 years.

Table 2: Parity status.

\begin{tabular}{|ll|}
\hline Parity & Number of patients \\
\hline Primigravida & $15(75 \%)$ \\
\hline Multigravida & $5(25 \%)$ \\
\hline
\end{tabular}

\section{Maternal outcomes}

In the present study adverse maternal outcomes including postpartum hemorrhage, perineal trauma, mortality was noted.
Table 3: Age wise distribution.

\begin{tabular}{|ll|}
\hline Age (years) & Total number of patients \\
\hline $20-25$ & $16(80 \%)$ \\
\hline $26-30$ & $04(20 \%)$ \\
\hline
\end{tabular}

In all cases, forceps application was done by the lead author with expertise in forceps delivery and in line with standard protocol and guidelines. All the cases in the present study underwent uneventful vaginal delivery under strict aseptic precautions. The postnatal period was also uneventful with exclusive breastfeeding established within few hours in all cases.

\section{Foetal outcomes}

The present study noted foetal outcomes in terms of Apgar score

- Birth weight

- $\quad$ Birth injuries

- $\quad$ NICU admission.

Average birth weight in the present study was $3.2 \mathrm{kgs}$ as shown in Table 4. Apgar score at birth and five minutes was within normal limits. None of the new-borns required NICU admission. Hence exclusive breastfeeding was started as soon as possible in all cases. Taking into consideration the expertise and protocol-based forceps application, no any birth injuries was noted in any of the new-borns.

\section{DISCUSSION}

The impact of chosen method of delivery on future modes of delivery is of vital importance in modern obstetrics. One of the leading factors in global rise of caesarean section is Primarily caesarean itself. Authors need to minimize the same to have a noticeable effect on the overall rate of caesarean section worldwide. This will also reduce the risk of intrapartum complications in subsequent pregnancies. ${ }^{5}$

In the present study all women underwent an uneventful outlet forceps assisted vaginally delivery. A prospective study observed that women were more likely to prefer a future vaginal delivery after a successful forceps' delivery. ${ }^{6}$ These women were more likely to achieve a vaginal delivery in subsequent pregnancies as compared to primary caesarean delivery.?

The most common indications for forceps application in the present study were maternal exhaustion, foetal distress and prolonged second stage. This findings are supported by the study conducted by Nicolov, where in fetal distress $(78.1 \%)$, was the most common indication followed by prolonged $2^{\text {nd }}$ stage $(23.6 \%) .{ }^{8}$ In another study conducted at a teaching hospital in Cameroon, the most common indication was prolonged $2^{\text {nd }}$ stage of labor 
followed by maternal exhaustion in study conducted by Yeomans. ${ }^{9,10}$

In the present study forceps were applied by the lead author with expertise and as per standard protocol leading to uneventful vaginal delivery in all cases. No any adverse maternal outcomes like perineal tears, postpartum hemorrhage, failure of forceps was observed in the present study as supported by the study conducted by Nkwabong. ${ }^{9}$ The minor lacerations if any were managed easily during episiotomy suturing.

Proper perineal support and hemostasis is important to prevent perineal tears along with proper selection of cases as in present study. and careful suturing cures most of the cases. The postnatal advice including soft solid diet for 48 hours with laxative at bed time and twice a day Perineal care enables adequate wound healing in such cases. Bollard et al, reported similar findings in his study. ${ }^{11}$

In the present study, all cases were discharged on postnatal day 3 after passing of stools and healthy episiotomy wounds with EBF established. delivery. Study conducted by Murphy found that major haemorrhage and prolonged stay in hospital were seen in women as compared with instrumental delivery as in the present study. ${ }^{12}$ This has an important role in cost implications to healthcare service providers and social benefits altogether globally.

In the present study no adverse foetal outcome was observed. Exclusive breastfeeding was started as early as possible after assessment of Apgar and excluding birth injuries. A study conducted in Australia also reported good neonatal outcomes, no perinatal deaths as observed in this study. ${ }^{13}$

As per the Evidence available forceps are associated with less failure and is quicker than by vacuum extraction, which is of critical in cases with fetal distress as in this study. ${ }^{14,15}$

As per Cochrane meta-analysis women with vaginal delivery were less anxious and satisfied as compared than women who had a caesarean section. They were also more likely to breast feed, positive reactions to their infants and interact with them more at home as in the present study. ${ }^{16}$

Practice guidelines and standard protocols are necessary for safe and consistent obstetric practice worldwide. Forceps delivery offers advantages over caesarean section including the potential for future spontaneous vaginal deliveries. $^{12}$

\section{CONCLUSION}

The art of Forceps delivery is a viable option to reduce the current rising caesarean section rates globally. Further research in this area will enable a better understanding of forceps.

Forceps delivery is thus a safe and effective option in modern day obstetrics to reduce the alarming rise in rates of caesarean section globally. Training should be encouraged to develop the expertise of this art of forceps delivery.

\section{Funding: No funding sources \\ Conflict of interest: None declared \\ Ethical approval: The study was approved by the Institutional Ethics Committee}

\section{REFERENCES}

1. Caughey AB, Cahill AG, Guise JM, Rouse DJ, American College of Obstetricians and Gynecologists. Safe prevention of the primary cesarean delivery. Am J Obstet Gynecol. 2014;210(3):179-93.

2. Martin JA, Hamilton BE, Ventura SJ, Osterman JK, Mathews TJ. Births: Final Data for 2011 National Vital Statistics Reports: National Center for Health Statistics. 20213;62(1):1-69.

3. O'Mahony F, Hofmeyr GJ, Menon V. Choice of instruments for assisted vaginal delivery. Cochrane Data Syst Rev. 2010;11:Article ID CD005455.

4. Gei AF, Belfort MA. Forceps-assisted vaginal delivery. Obstet Gynecol Clin North Am. 1999;26(2):345-70.

5. Thomas J, Paranjothy S. National sentinel caesarean section audit report. London: Royal College of Obstetricians and Gynaecologists Clinical Effectiveness Support Unit; 2001.

6. Murphy DJ, Liebling RE. Cohort study of maternal view son future mode of delivery following operative delivery in the second stage of labor. Am J Obstetr Gynecol. 2003;188:542-8.

7. Bahl R, Strachan B, Murphy DJ. Outcome of subsequent pregnancy three years after previous operative delivery in the second stage of labour: cohort study. BMJ. 2004;328:311-6.

8. Nikolov A, Nashar S, Atanasova M, Dimitrov A. Indications for vaginal delivery with forceps application. Akush Ginekol (Sofiia). 2011;50:3-12.

9. Nkwabong E, Nana PN, Mbu R, Takang W, Ekono MR, Kouam L. Indications and maternofetal outcome of instrumental deliveries at the University Teaching Hospital of Yaounde, Cameroon. Trop Doct. 2011;41:5-7.

10. Yeomans ER. Operative vaginal delivery. Obstet Gynecol. 2010;115:645-53.

11. Bollard RC, Gardiner A, Duthie GS, Lindow SW. Anal sphincter injury, fecal and urinary incontinence: A 34-year follow-up after forceps delivery. Dis Colon Rectum. 2003;46:1083-8.

12. Murphy DJ, Liebling RE, Verity L, Swingler R, Patel R. Cohort study of the early maternal and neonatal morbidity associated with operative 
delivery in the second stage of labour. Lancet. 2001;358:1203-7.

13. Chow SL, Johnson CM, Anderson TD, Hughes JH. Rotational delivery with Kielland's forceps. Med J Aust. 1987;146:616-9.

14. Johanson RB. Instrumental vaginal delivery. London: Royal College of Obstetricians and Gynaecologists; 2000.

15. Mesleh RA, Al-Sawadi HM, Kurdi AM. Comparison of maternal and infant outcomes between vacuum extraction and forceps deliveries. Saudi Med J. 2002;23:811-3.
16. DiMatteo MR, Morton SC, Lepper HS, Damush TM, Carney MF, Pearson M, et al. Cesarean childbirth and psychosocial outcomes: a meta-analysis. Health Psychology. NHS Centre for Reviews and Dissemination. 1996;15:303-14.

Cite this article as: Pitale DL. Effectiveness of forceps delivery in modern day obstetrics. Int J Reprod Contracept Obstet Gynecol 2020;9:2836-9. 